\title{
In vitro Assays and Imaging Methods for Drug Discovery for Cardiac Fibrosis
}

\section{Giorgia Palano', Ariana Foinquinos² and Erik Müllers²*}

'Division of Physiological Chemistry I, Department of Medical Biochemistry and Biophysics, Karolinska Institutet, Stockholm, Sweden, ${ }^{2}$ Bioscience Cardiovascular, Research and Early Development, Cardiovascular, Renal and Metabolism,

BioPharmaceuticals R\&D, AstraZeneca, Gothenburg, Sweden

As a result of stress, injury, or aging, cardiac fibrosis is characterized by excessive deposition of extracellular matrix (ECM) components resulting in pathological remodeling, tissue stiffening, ventricular dilatation, and cardiac dysfunction that contribute to heart failure (HF) and eventually death. Currently, there are no effective therapies specifically targeting cardiac fibrosis, partially due to limited understanding of the pathological mechanisms and the lack of predictive in vitro models for highthroughput screening of antifibrotic compounds. The use of more relevant cell models, three-dimensional (3D) models, and coculture systems, together with high-content imaging $(\mathrm{HCl})$ and machine learning $(\mathrm{ML})$-based image analysis, is expected to improve predictivity and throughput of in vitro models for cardiac fibrosis. In this review, we present an overview of available in vitro assays for cardiac fibrosis. We highlight the potential of more physiological 3D cardiac organoids and coculture systems and discuss $\mathrm{HCl}$ and automated artificial intelligence (Al)-based image analysis as key methods able to capture the complexity of cardiac fibrosis in vitro. As 3D and coculture models will soon be sufficiently mature for application in large-scale preclinical drug discovery, we expect the combination of more relevant models and high-content analysis to greatly increase translation from in vitro to in vivo models and facilitate the discovery of novel targets and drugs against cardiac fibrosis.

Keywords: cardiac fibrosis, in vitro assays, 3D models, co-culture systems, high-content imaging, drug discovery

\section{INTRODUCTION}

Cardiac fibrosis is a common feature in the pathology of many forms of cardiovascular diseases. It is characterized by excessive production and deposition of extracellular matrix (ECM) components in the connective tissue of the heart, mainly collagens, that confer stiffness and loss of contractility, thereby reducing cardiac function (reviewed in Kong et al., 2014; Liu et al., 2017).

Received: 21 April 2021 Accepted: 07 June 2021 Published: 08 July 2021

Citation:

Palano G, Foinquinos $A$ and Müllers E (2021) In vitro Assays and Imaging Methods for Drug Discovery for Cardiac Fibrosis.

Front. Physiol. 12:697270. doi: 10.3389/fphys.2021.697270
Abbreviations: 3D, three-dimensional; AI, artificial intelligence; ECM, extracellular matrix; TGF- $\beta$, transforming growth factor-beta; PDGF, platelet-derived growth factor; TNF $\alpha$, tumor necrosis factor-alpha; HF, heart failure; IL-1 $\beta$, interleukin1 beta; TAK1, transforming growth factor- $\beta$-activated kinase 1 ; JNK, $c$-Jun $\mathrm{N}$-terminal kinase; PI3K, phosphoinositide 3-kinase; RhoA, Ras homolog family member A; $\alpha$-SMA, alpha-smooth muscle actin; MMPs, matrix metalloproteinases; $\mathrm{CCN} 2$, connective tissue growth factor; RT-qPCR, real-time quantitative polymerase chain reaction; IF, immunofluorescence; ELISA, enzyme-linked immunosorbent assay; WB, Western blot; PICP, procollagen type I carboxy-terminal propeptide; SEM, scanning electron microscopy; HPCL, high-performance liquid chromatography; LC-MS, liquid chromatographymass spectrometry; MS, mass spectrometry; iPSCs, induced pluripotent stem cells; HCI, high-content imaging; RAAS, renin-angiotensin-aldosterone system; ML, machine learning. 
At the cellular level, the main cells responsible for cardiac fibrosis are cardiac fibroblasts (CFs), which are producing collagen and other ECM proteins. Following cardiac injury, CFs become activated and can differentiate into myofibroblasts (myoFBs), a cell type exhibiting stress fibers and characterized by the expression of alpha-smooth muscle actin ( $\alpha$-SMA) and other contractile proteins (Gabbiani et al., 1971; Skalli et al., 1989). It is well known that one of the molecular mechanisms driving cardiac fibrosis is the transforming growth factor-beta (TGF- $\beta$ ) signaling pathway. TGF- $\beta$ is a potent inducer of collagen synthesis that can induce phenotypic changes in CFs and their differentiation into myoFBs (Desmouliere et al., 1993). MyoFBs secrete high levels of ECM proteins, such as collagens, including collagen type I, which is the most abundant protein of the cardiac ECM and the main component of fibrotic tissue. It is synthesized as a collagen precursor (procollagen) that is processed to form mature collagen, which is released into the extracellular space (reviewed in Canty and Kadler, 2005). The excessive accumulation of mature collagen and deposition of ECM can lead to either reparative fibrosis or reactive fibrosis. Reparative fibrosis is mainly seen after an acute myocardial infarction (MI) to replace dead cardiomyocytes with fibrotic scar tissue or in end-stage heart failure (HF). Also, reactive fibrosis is seen after MI and HF, but it mainly occurs as a pathological condition related to age and $\mathrm{HF}$ with preserved ejection fraction (HFpEF) (Heymans et al., 2015).

Preclinical studies indicate that cardiac fibrosis can be attenuated, reduced, and even reversed by the pharmaceutical intervention (Nagaraju et al., 2019). Thus, there is an enormous interest to find new treatments for cardiac fibrosis and to better understand its pathogenesis. New promising pathways involving several noncoding RNAs, such as microRNA 21 (miRNA-21), miR-208a, nuclear enriched abundant transcript 1 (Neat1), and maternally expressed 3 (Meg 3), have emerged in preclinical studies. Also, candidates like galectin-3 (Gal-3), neutrophil gelatinase-associated lipocalin (NGAL), cardiotrophin-1 (CT-1), and NADPH oxidase 2 (NOX2) have been associated clinically and preclinically with collagen dysregulation (Sharma et al., 2004; Yndestad et al., 2009; Murdoch et al., 2014; Heymans et al., 2015; Piccoli et al., 2017; Kenneweg et al., 2019).

Physiologically relevant, predictive, and reliable in vitro assays are required to study the underlying molecular mechanisms and to find drugs against cardiac fibrosis. In this study, we review different assays and imaging methods to detect cardiac fibrosis in vitro, and we discuss the challenges and future directions of the development of novel assays.

\section{IN VITRO ASSAYS FOR CARDIAC FIBROSIS}

\section{Challenges Assessing Cardiac Fibrosis in vitro}

Cardiac fibrosis is a complex, multistep cellular and molecular process that takes weeks to months in vivo and has, thus, proven difficult to recapitulate in vitro. Progress to develop physiologically relevant cardiac cell culture models has been slower compared to other organ tissues, for example, kidney, liver, or tumors. The discovery of treatments for cardiac fibrosis has, therefore, been hampered by the lack of reliable and predictive in vitro assays with sufficient throughput for drug discovery. An ideal cardiac fibrosis assay needs to recapitulate multiple, highly complex processes, such as:

(a) Formation of myoFBs, which differentiate from fibroblasts or epithelial to mesenchymal trans-differentiation upon induction of cytokine, and differentiation to CFs (Bryant et al., 2009; Li et al., 2016).

(b) Activation/differentiation of fibroblasts, driven by multiple cytokine stimuli such as TGF- $\beta$, angiotensin II, plateletderived growth factor (PDGF), endothelin-1, tumor necrosis factor-alpha $(\mathrm{TNF} \alpha)$, interleukin-1 beta (IL$1 \beta)$, and others, inflammation-mediated or triggered by mechanical stress (reviewed in Aujla and Kassiri, 2021).

(c) Activation of multiple canonical (e.g., Smad3/4) and noncanonical [e.g., transforming growth factor$\beta$-activated kinase 1 (TAK1), c-Jun N-terminal kinase (JNK), phosphoinositide 3-kinase (PI3K), and Ras homolog family member A (RhoA) (reviewed in Zhang, 2017) signaling pathways, resulting in the induction of fibrogenic gene transcription] encoding proteins such as $\alpha$-SMA, collagen, matrix metalloproteinases (MMPs), and connective tissue growth factor (CCN2), which increase deposition of collagen and other ECM proteins.

(d) Production, secretion, processing, and maturation of ECM proteins such as collagens (Canty and Kadler, 2005).

Thus, there are multiple challenges to recapitulating cardiac fibrosis in a dish (Figure 1A). The ideal cardiac fibrosis assay should build on physiologically relevant cells and needs to incorporate relevant readouts. In order to be applicable for drug screening, it needs to be robust, cost- and time-effective, and high-throughput. If possible, it should recapitulate the effects of three-dimensional (3D) structure and incorporate multiple relevant cell types involved. Finding the ideal in vitro assay is a complex puzzle of many pieces (Figure 1B).

\section{Readouts of Cardiac Fibrosis Assays}

Naturally, in vitro assays can only recapitulate parts of the in vivo situation. MyoFB is central to cardiac fibrosis and, thus, to any cardiac fibrosis in vitro assay. Formation of myoFB and activation of fibroblast can result from different cell types and integrating several major biochemical pathways (Figure 2A). In principle, any of these pathways and their downstream signaling can provide the basis for an assay readout. Notably, an in vitro assay is often limited to a single or few cell types (see sections "Cell Models" and "Three-Dimensional Models and Coculture Systems"), therefore, limiting the possibility of paracrine fibroblast activation. In fibroblast-only cell culture, TGF- $\beta$ is the major pathway for activation of fibroblast and the stimulus of choice for the majority of cardiac fibrosis assays (Figure 2B). 

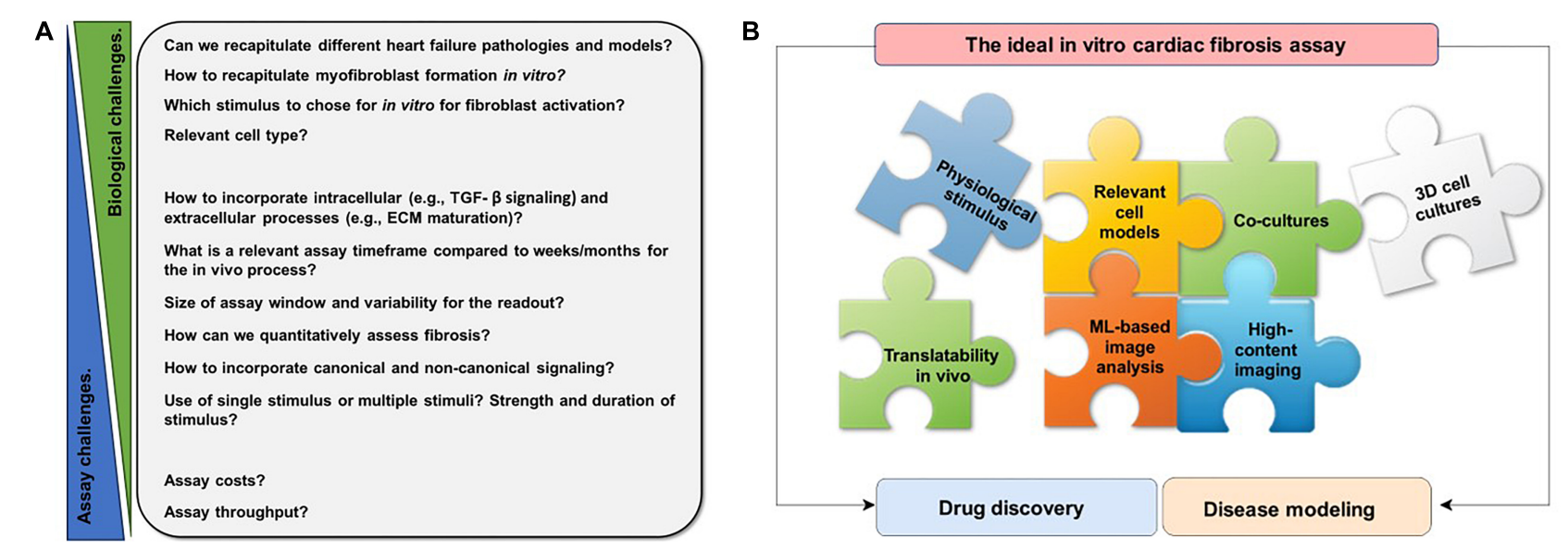

FIGURE 1 | Schematic overview of challenges of recapitulating cardiac fibrosis in vitro and features of an ideal in vitro cardiac fibrosis assay. (A) Numerous challenges have to be overcome to recapitulate the complex, multistep process of cardiac fibrosis in vitro. These are challenges of fibroblast biology, challenges in assay development, or in between. (B) Each puzzle piece represents a feature that should be taken into account for the ideal in vitro cardiac fibrosis assay. Many different aspects, such as physiological stimulus, relevant cell models, cocultures, three-dimensional (3D) cell culture, high-content imaging, machine learning (ML)-based analysis, translatability to in vivo, and need to be considered for a physiologically relevant in vitro cardiac fibrosis assay.

Current cardiac fibrosis assays can broadly be divided into four groups based on their main readout: (a) TGF- $\beta$ pathway activation/TGF- $\beta$-dependent gene expression; (b) $\alpha$-SMA expression; (c) (mature) collagen detection; and (d) fibroblast proliferation or migration (Figure 2B and Table 1).

Due to the complexity of fibrosis in vivo, it is very difficult to mimic with a single in vitro assay. Typically, each assay aims to model a key event in the fibrotic pathway, such as myoFB differentiation, TGF- $\beta$ pathway activation, or collagen production. These assays are well suited to capture the respective parts of the fibrotic process and to evaluate specific effects of compounds in vitro; nonetheless, the current assays have a poor history of finding hits that translate to clinical applications. The reasons for this are manifold. Target- or biomarker-specific assays capture a single process very well but do not capture cardiac fibrosis as a whole. Reporter cell lines for TGF- $\beta$-dependent gene expression allow for robust, cell-based, and high-throughput screening (Tesseur et al., 2006). However, the engineered cells do not fully reflect the physiology of CFs. Hits are likely limited to the TGF- $\beta$ receptor $\rightarrow$ SMAD3/4 $\rightarrow$ TGF- $\beta$-dependent gene expression signaling axis and, thus, limited to early signaling nodes and TGF- $\beta$ as a stimulus. Such assays can provide valuable information for target deconvolution, i.e., they can indicate or exclude specific target/pathway activity if the target or mechanism of action for a hit compound is not known. As such, they should be integral parts of a drug-screening cascade for cardiac fibrosis.

Similarly, assays that measure biomarkers, such as quantification of PICP (propeptide of procollagen type I) or hydroxyproline, can provide valuable information in a drugscreening cascade. Assessing these biomarkers in vitro increases the understanding of the mechanism of action of a compound and, thus, improves the chances for in vivo translation. As such, these types of assays are best suited for not only initial high-throughput screening (HTS) but also downstream profiling of hits.

Alpha-smooth muscle actin protein expression is an early hallmark in cardiac fibrosis. Many high-quality immunoreagents are available, and thus, especially immunofluorescence of $\alpha$-SMA has emerged as an attractive readout to screen for compounds with antifibrotic activity in the heart (Rehman et al., 2019) or other tissues (Sieber et al., 2018; Weigle et al., 2019). Formation and secretion of mature collagen follow further downstream of TGF- $\beta$ and $\alpha$-SMA (Figure 2B). Quantification of mature collagen integrates upstream signaling, and, as a major component of excessive production of ECM, collagen contributes to the in vivo pathomechanism. However, there are many different forms of collagen and assays and reagents to specifically and quantitatively assess whether mature collagen is sparse. Interestingly, several recent screening approaches utilize immunofluorescence of both $\alpha$-SMA and collagen, which could be seen as the first step to a multiparametric approach (Weigle et al., 2019; Turner et al., 2020).

Schimmel et al. (2020) analyzed three readouts, namely, the proliferation of human $\mathrm{CFs}$, modulation of apoptosis, and expression of ECM, when screening a natural compound library for molecules for the treatment of cardiac fibrosis. Sieber et al. (2018) combined high-content imaging (HCI) with an impedance-based assay and multiplexed quantification of $\alpha$-SMA and collagen $1 \alpha$. The incorporation of multiple readouts adds additional information and reduces the intrinsic bias in any screening assay (Abraham et al., 2014). Omics-type approaches, such as transcriptomics, proteomics, and phenomics (i.e., HCI), are phenotypic drug discovery approaches and as such provide the opportunity to discover novel targets or compounds with novel mechanisms of action. Although less biased and very rich in information, they require special infrastructure, expertise, and 


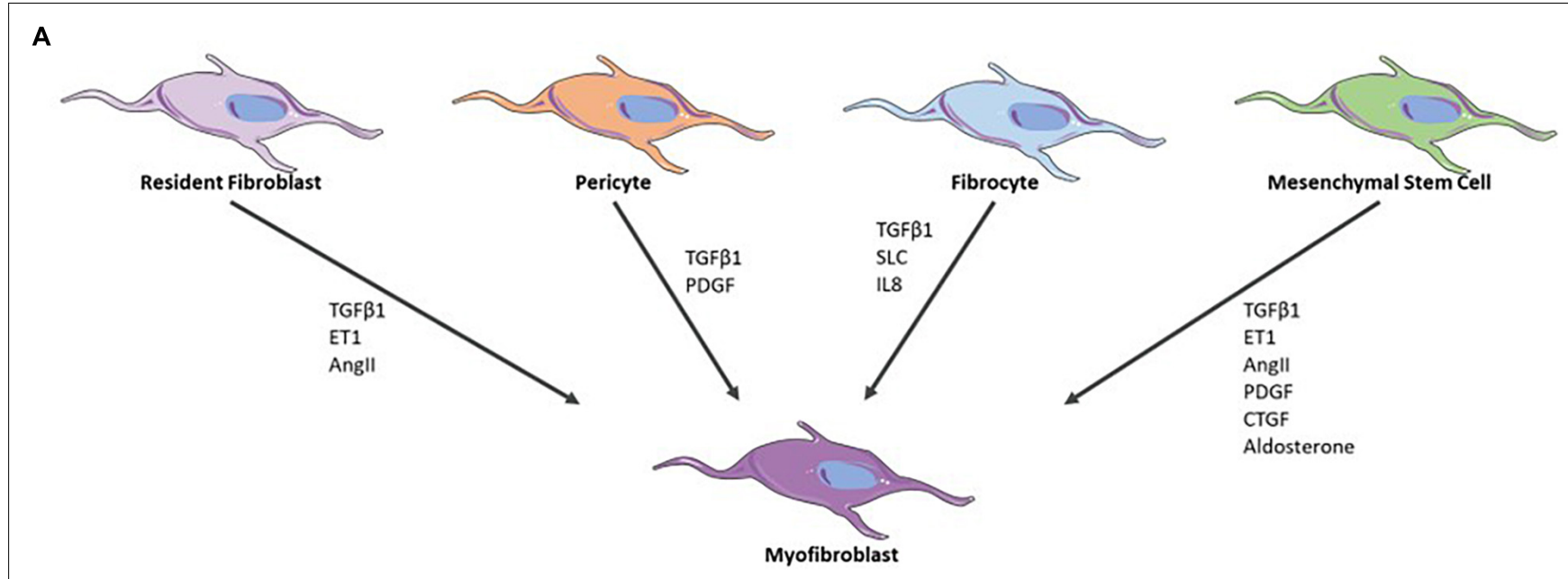

B

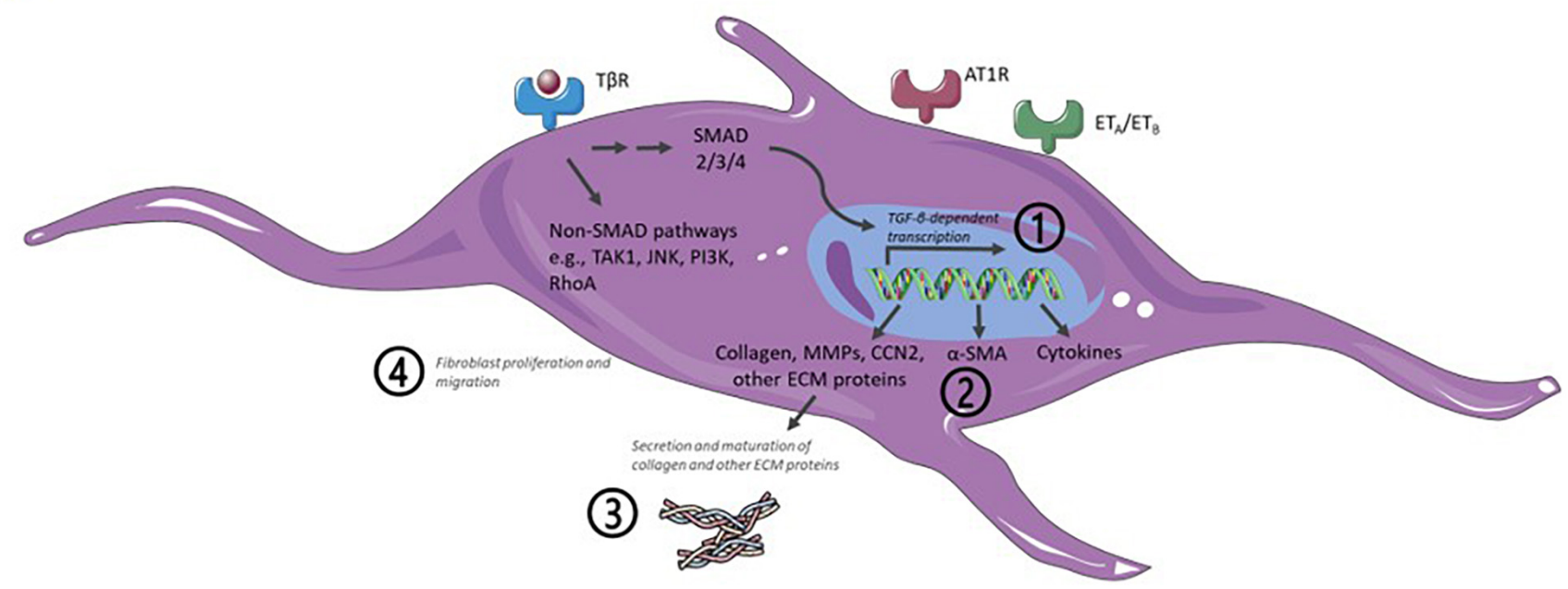

FIGURE 2 | Schematic representation of major biochemical pathways involved in the formation of myofibroblasts (myoFBs), activation of cardiac fibroblasts (CFs), profibrotic signaling, and key readouts for in vitro assays. (A) In vivo formation of myoFBs occurs from different cell types including resident fibroblasts, pericytes, fibrocytes, or mesenchymal stem cells, stimulated by mediators such as TGFß1, ET1 (endothelin 1), Angll (angiotensin II), PDGF (platelet-derived growth factor), SLC (secondary lymphoid chemokine), IL8 (interleukin-8), CTGF (connective tissue factor), or aldosterone. (B) Activation of CFs is triggered by a myriad of cytokines and growth factors, such as TGF- $\beta$, CCN2 (connective tissue factor 2), PDGFs, Angll, aldosterone, endothelin-1, TNF $\alpha$ (tumor necrosis factor $\alpha$ ), IL 1- $\beta$ (interleukin-1 $\beta$ ), or IL6 (interleukin-6). Activation of TGF- $\beta$ receptor (TRR) leads to activation of downstream canonical SMAD and noncanonical pathways. The majority of cardiac fibrosis assays rely on measuring one of four major readouts: (Kong et al., 2014) TGF- $\beta$ pathway activation/TGF- $\beta$-dependent gene expression; (Liu et al., 2017) $\alpha$-SMA expression; (Gabbiani et al., 1971) (mature) collagen detection; and (Skalli et al., 1989) fibroblast proliferation or migration. Angiotensin II receptor type 1-mediated (AT1R) signaling and endothelin receptor-mediated $\left(\mathrm{ET}_{A} / \mathrm{ET}_{B}\right)$ signaling also contribute to cardiac fibrosis. As an excellent, in-depth review of signaling for the formation of myoFB and activation of CF, the reader is referred to the study of Aujla and Kassiri (2021). Figure created using Servier Medical Art by Servier (https://smart.servier.com/), licensed under a Creative Commons Attribution 3.0 Unported License.

resources to deconvolute the hits from a screen (also see section "High-Content Imaging").

\section{Cell Models}

The in vitro cell model is of high importance for antifibrotic effects to translate to in vivo. More physiologically relevant cell models often come with higher complexity and, thus, lower throughput for drug screening (Horvath et al., 2016; Table 2).
The NIH 3T3 murine fibroblast cell line is a widely used cell line for proof-of-concept studies due to their high cell proliferation rate and easy handling in cell culture. TGF- $\beta 1$ treatment of NIH 3T3 fibroblasts results in transformation into activated myoFBs with characteristics of $\alpha$-SMA (Desmouliere et al., 1993) and collagen expression (Grande et al., 1997). Primary fibroblasts isolated from rat or murine hearts are an alternative model that many researchers chose for their translational advantages 
TABLE 1 | Examples of assays to assess features of cardiac fibrosis in vitro.

\begin{tabular}{|c|c|c|c|}
\hline Assay readout & $\begin{array}{l}\text { Method (example } \\
\text { references) }\end{array}$ & Advantages & Limitations \\
\hline $\begin{array}{l}\text { TGF- } \beta \text {-dependent gene } \\
\text { expression }\end{array}$ & $\begin{array}{l}\text { RT-qPCR } \\
\text { (Ranganathan et al., 2007) }\end{array}$ & $\begin{array}{l}\text { - High sensitivity } \\
\text { - Quantitative analysis }\end{array}$ & $\begin{array}{l}\text { - Often measurement of a single/a few gene(s) } \\
\text { only }\end{array}$ \\
\hline $\begin{array}{l}\text { TGF- } \beta \text { dependent gene } \\
\text { expression }\end{array}$ & $\begin{array}{l}\text { Reporter cell lines } \\
\text { (Tesseur et al., 2006) }\end{array}$ & $\begin{array}{l}\text { - High-throughput }{ }^{a} \\
\text { - Quantitative analysis }\end{array}$ & $\begin{array}{l}\text { - Bias to a single promoter readout } \\
\text { - Requires cell line engineering }\end{array}$ \\
\hline $\begin{array}{l}\alpha \text {-SMA protein } \\
\text { expression }\end{array}$ & $\begin{array}{l}\text { IF staining } \\
\text { (Shinde et al., 2017; } \\
\text { Baranyi et al., 2019) }\end{array}$ & $\begin{array}{l}\text { - Allows assessment of intracellular localization and } \\
\text { single-cell analysis } \\
\text { - Quantitative analysis } \\
\text { - Can be set up in high-throughput } \\
\text { - Sensitive to changes in cell number and density }\end{array}$ & $\begin{array}{l}\text { - Requires quantitative fluorescence microscopy } \\
\text { instruments } \\
\text { - Dependent on good, specific immunoreagents } \\
\text { - Requires only low cell number }\end{array}$ \\
\hline $\begin{array}{l}\text { Collagen protein } \\
\text { expression }\end{array}$ & Western blot & $\begin{array}{l}\text { - Detection of different forms and type } \\
\text { - Semi-quantitative analysis }\end{array}$ & $\begin{array}{l}\text { - Antibodies exist only in specific forms and } \\
\text { types of collagen } \\
\text { - Highly dependent on immunoreagents } \\
\text { - Requires larger amounts of cells }\end{array}$ \\
\hline $\begin{array}{l}\text { Collagen protein } \\
\text { expression }\end{array}$ & ELISA (Baranyi et al., 2019) & $\begin{array}{l}\text { - High sensitivity and specificity } \\
\text { - Quantitative analysis } \\
\text { - Can be set up in high-throughput } \\
\text { - Requires less material than WB }\end{array}$ & - Dependent on immunoreagents \\
\hline $\begin{array}{l}\text { Visualization of collagen } \\
\text { fibers }\end{array}$ & $\begin{array}{l}\text { Sirius Red dye } \\
\text { (Junqueira et al., 1979; } \\
\text { Whittaker et al., 1994) }\end{array}$ & $\begin{array}{l}\text { - Mature collagen fiber formation is a late hallmark of } \\
\text { cardiac fibrosis } \\
\text { - Semi-quantitative analysis }\end{array}$ & - In vivo method that is difficult to adapt to in vitro \\
\hline $\begin{array}{l}\text { Visualization of collagen } \\
\text { fibers }\end{array}$ & Masson's trichrome staining & $\begin{array}{l}\text { - Mature collagen fiber formation is a late hallmark of } \\
\text { cardiac fibrosis } \\
\text { - Semi-quantitative analysis }\end{array}$ & - In vivo method that is difficult to adapt to in vitro \\
\hline $\begin{array}{l}\text { Collagen peptide } \\
\text { detection }\end{array}$ & $\begin{array}{l}\text { PIP } \\
\text { (Querejeta et al., 2000, 2004) }\end{array}$ & $\begin{array}{l}\text { - In vivo biomarker that can be adapted to in vitro } \\
\text { - Quantitative analysis } \\
\text { - Potentially high-throughput }\end{array}$ & $\begin{array}{l}\text { - Bias to a single-marker readout that is not fully } \\
\text { specific for cardiac fibrosis }\end{array}$ \\
\hline $\begin{array}{l}\text { Direct visualization of } \\
\text { collagen fibers }\end{array}$ & Electron microscopy & $\begin{array}{l}\text { - Mature collagen fiber formation is a late hallmark of } \\
\text { cardiac fibrosis }\end{array}$ & $\begin{array}{l}\text { - No quantitative analysis } \\
\text { - Requires electron microscopy equipment and } \\
\text { expertise, usually only available in highly } \\
\text { specialized laboratories } \\
\text { - Low throughput } \\
\text { - Does not distinguish different types and forms }\end{array}$ \\
\hline $\begin{array}{l}\text { Hydroxyproline } \\
\text { quantification }\end{array}$ & $\begin{array}{l}\text { HPCL/LC-MS } \\
\text { (Qiu et al., 2014) }\end{array}$ & $\begin{array}{l}\text { - In vivo biomarker that can be adapted to in vitro } \\
\text { - Quantitative analysis }\end{array}$ & $\begin{array}{l}\text { - Requires HPLC capabilities, mass spectrometry } \\
\text { equipment, and high-level of } \\
\text { technology-specific expertise } \\
\text { - Bias to a single-marker readout that is not } \\
\text { specific for cardiac fibrosis }\end{array}$ \\
\hline Collagen detection & MS (van Huizen et al., 2020) & $\begin{array}{l}\text { - Possible to detect different forms and types of collagen } \\
\text { - Semi-quantitative analysis }\end{array}$ & $\begin{array}{l}\text { - Low throughput } \\
\text { - Requires mass spectrometry instrument and } \\
\text { high-level of technology-specific expertise }\end{array}$ \\
\hline $\begin{array}{l}\text { Cardiac fibroblast } \\
\text { migration }\end{array}$ & $\begin{array}{l}\text { Cell migration assay (scratch } \\
\text { assay) (Liang et al., 2007) }\end{array}$ & $\begin{array}{l}\text { - Semi-quantitative analysis } \\
\text { - Medium throughput }\end{array}$ & - Can be adapted for 3D and coculture models \\
\hline $\begin{array}{l}\text { Cardiac fibroblast } \\
\text { proliferation }\end{array}$ & $\begin{array}{l}\text { Cell count or proliferation } \\
\text { markers }\end{array}$ & $\begin{array}{l}\text { - Quantitative analysis } \\
\text { - Low cost and high-throughput } \\
\text { - Adaptable for IF staining and imaging } \\
\text { - Can be combined with ELISA and/or flow cytometry } \\
\text { - Can be adapted for 3D and coculture models }\end{array}$ & $\begin{array}{l}\text { - Counter-screening required to identify } \\
\text { fibroblast-specific proliferators } \\
\text { - Fibroblast proliferation is not predictive for } \\
\text { cardiac fibrosis }\end{array}$ \\
\hline $\begin{array}{l}\text { Multiparametric } \\
\text { readout, i.e., } \\
\text { phenotypic fingerprints }\end{array}$ & $\begin{array}{l}\text { Transcriptomics or } \\
\text { proteomics } \\
\text { (Barallobre-Barreiro et al., } \\
\text { 2012; Abonnenc et al., 2013; } \\
\text { Jonsson et al., 2016) }\end{array}$ & $\begin{array}{l}\text { - Multiple parameters integrated to score fibrosis } \\
\text { phenotype } \\
\text { - Allows for unbiased detection of also unknown } \\
\text { phenotypes }\end{array}$ & $\begin{array}{l}\text { - Necessary instrumentation is usually only } \\
\text { available in highly specialized laboratories } \\
\text { - Requires infrastructure for data handling and } \\
\text { specific expertise for data analysis } \\
\text { - High cost and low throughput } \\
\text { - Little precedence for in vitro application } \\
\text { - Readouts can be difficult to interpret }\end{array}$ \\
\hline
\end{tabular}


TABLE 1 | Continued

\begin{tabular}{|c|c|c|c|}
\hline Assay readout & $\begin{array}{l}\text { Method (example } \\
\text { references) }\end{array}$ & Advantages & Limitations \\
\hline $\begin{array}{l}\text { Multiparametric } \\
\text { readout, i.e., } \\
\text { phenotypic fingerprints }\end{array}$ & $\begin{array}{l}\text { High-content imaging } \\
\text { (Pantazis et al., 2010; } \\
\text { Palano et al., 2020) }\end{array}$ & $\begin{array}{l}\text { - Multiple parameters integrated to score fibrosis } \\
\text { phenotype } \\
\text { - Allows for unbiased detection of also unknown } \\
\text { phenotypes } \\
\text { - Low cost and high-throughput } \\
\text { - Single-cell analysis }\end{array}$ & $\begin{array}{l}\text { - Requires quantitative fluorescence microscopy } \\
\text { instruments } \\
\text { - Requires infrastructure for data handling and } \\
\text { specific expertise for data analysis }\end{array}$ \\
\hline
\end{tabular}

${ }^{a}$ An assay is considered high-throughput if it can generally be run in 96-well format at reagent costs > $1 \$$ per data point.

(Sahadevan and Allen, 2021). Using primary cells requires specific techniques of cell isolation and culture to maintain them for a limited amount of passages. Special care is to be taken as cultured primary fibroblasts differentiate into myoFBs in vitro upon prolonged culture and repeated passaging (Santiago et al., 2010). From a translational point of view, human primary fibroblasts derived from cardiac tissue are the leading choice. They are commercially available and allow us to study the remodeling of both physiological and pathological cardiac matrix. However, primary fibroblasts can be transformed after prolonged culture (Baranyi et al., 2019). Other important factors to consider when using primary fibroblasts in drug screening campaigns are the need for supply of large amounts of cells and donor-to-donor variations, i.e., the risk that findings might be specific to a certain donor. The use of immortalized primary CFs can mitigate some of these issues and thus reduce assay variability.

\section{Three-Dimensional Models and Coculture Systems}

Two-dimensional (2D) monocultures are inherently unable to represent the complexity of in vivo cardiac structure, dynamics, and microenvironment. The development of 3D models and coculture systems could help to better mimic antifibrotic effects in vitro.

Multiple 3D cardiac organoid systems have been described (reviewed in Zuppinger, 2019). Organoids can be generated from induced pluripotent stem cells (iPSCs) that can be differentiated into different cardiac cell types, such as cardiomyocytes, endothelial cells, and fibroblasts (Filippo Buono et al., 2020). Alternatively, organoids can be generated from patient-derived primary cells, which of one or several cell types. Combinations of iPSCs, primary cells, and/or cell lines also exist. As 3D cardiac organoids can better recapitulate structure, cell composition, and function of heart tissue, they improve upon current multi-scaled drug screening platforms including in vitro assays and modeling diseases like cardiac fibrosis (Nugraha et al., 2018). The 3D models are currently being developed to fully recapitulate the composition of ECM, spatial distributions of cells, architectural organization of ECM, and cell crosstalk. Thus, 3D cardiac organoids are an attractive alternative in vitro model for cardiac diseases and HF. They are a promising tool for drug screening and assessing cardiotoxic effects, proliferation, and cell viability (Polonchuk et al., 2017) and can potentially contribute to the development of more physiologically relevant preclinical
TABLE 2 | Cell models used in in vitro cardiac fibrosis assays.

\begin{tabular}{|c|c|c|}
\hline Cell model & Advantages & Limitations \\
\hline $\begin{array}{l}\text { NIH } 3 \text { T3 murine } \\
\text { fibroblasts }\end{array}$ & $\begin{array}{l}\text { - High cell proliferation rate } \\
\text { - Easy handling } \\
\text { - Unlimited cell supply }\end{array}$ & $\begin{array}{l}\text { - Limited translation to } \\
\text { in vivo studies }\end{array}$ \\
\hline $\begin{array}{l}\text { Primary rat or murine } \\
\text { cardiac fibroblasts }\end{array}$ & $\begin{array}{l}\text { - Higher physiological } \\
\text { relevance } \\
\text { - Better translation to in vivo } \\
\text { as mouse or rat is often the } \\
\text { first in vivo model }\end{array}$ & $\begin{array}{l}\text { - Requires specific } \\
\text { techniques of isolation } \\
\text { and culture } \\
\text { - Cells differentiate to } \\
\text { myofibroblasts upon } \\
\text { prolonged culture } \\
\text { - Limited amount of } \\
\text { passages }\end{array}$ \\
\hline $\begin{array}{l}\text { Primary human } \\
\text { cardiac fibroblasts }\end{array}$ & $\begin{array}{l}\text { - Higher likelihood for } \\
\text { translation to clinical studies } \\
\text { - Allow to study physiological } \\
\text { and pathological matrix } \\
\text { remodeling }\end{array}$ & $\begin{array}{l}\text { - Can be transformed } \\
\text { after prolonged culture } \\
\text { - Limited cell supply } \\
\text { - High costs } \\
\text { - Donor-to-donor } \\
\text { variations }\end{array}$ \\
\hline $\begin{array}{l}\text { Immortalized human } \\
\text { cardiac fibroblasts }\end{array}$ & $\begin{array}{l}\text { - Higher likelihood for } \\
\text { translation to clinical studies } \\
\text { - Larger amount of passages } \\
\text { - Reduces assay variability }\end{array}$ & - High costs \\
\hline
\end{tabular}

platforms to better predict in vivo drug efficacy. They can also be used for drug discovery for personalized medicine (Nugraha et al., 2019).

Coculture systems of different cardiac cell types have been developed both in 2D and 3D. Coculture of multiple cardiac cell types can better model disease features such as cardiac fibrosis (Baudino et al., 2008). However, finding physiologically relevant coculture models to develop cardiac fibrosis assays is challenging. Among others, it needs to identify optimal cell types (Pinto et al., 2016; Litvinukova et al., 2020), culture conditions (Zuppinger, 2019), and coculture cell ratios (Pinto et al., 2016), so that the coculture better mimics the in vivo situation.

From the perspective of an assay, it is important to understand whether a 3D and/or coculture model has greater physiological relevance, i.e., predictivity, for cardiac fibrosis. To adequately compare models, it is essential to use holistic, integrative readouts, i.e., a better model might show more in vivo-like (Kong et al., 2014) gene expression (Chothani et al., 2019), (Liu et al., 2017) protein expression, (Gabbiani et al., 1971) organoid structure and cellular composition (Lee et al., 2019), 
or (Skalli et al., 1989) more in vivo-like functional response, that is, higher predictivity for known modulators of cardiac fibrosis (Palano et al., 2020).

We are currently on the brink, where not only 2D but also $3 \mathrm{D}$ and coculture models are constantly improved and display their greater relevance. They will soon reach sufficient throughput, cost-effectiveness, and robustness for applications in large-scale drug screening.

\section{HIGH-CONTENT IMAGING}

\section{High-Content Imaging to Measure Cardiac Fibrosis in vitro}

High-content imaging is a particularly attractive method to assay complex phenotypes such as cardiac fibrosis. Traditionally, HCI has been used as a cost-effective way to assess one or a few readouts that are thought to be most relevant for the process, e.g., antibody staining for $\alpha$-SMA levels or certain forms of collagen as a proxy for cardiac fibrosis (see section "Readouts of Cardiac Fibrosis Assays"). Nowadays, staining, imaging, and image analysis can be automated in multi-well format, which allows to minimize the number of precious cells, reduces the number of reagents needed, and, thus, reduces costs, while at the same time increasing throughput and robustness. Modern image analysis methods allow us to integrate hundreds of parameters from microscopy images, i.e., creating a phenotypic profile instead of a single-marker readout [reviewed in Warchal et al. (2016); Scheeder et al. (2018)].

\section{A Phenotypic High-Throughput in vitro Cardiac Fibrosis Assay}

We recently established cell culture conditions that promote deposition of mature collagen from primary human CFs in vitro (Palano et al., 2020). Based on these conditions, we set up a high-content immunofluorescence assay allowing for high-throughput, phenotypic identification of compounds with antifibrotic activity (Palano et al., 2020). Features extracted from the microscopy images, such as fluorescence intensity, cellular morphology, and staining texture, served as a basis for a linear classifier to classify cells into fibrotic or non-fibrotic phenotype. The assay can be run at low costs in 96-well or 384-well format, allowing to robustly assess the values of dose dependency and half-maximal effective concentration (EC50) potency for potential antifibrosis in vitro. Our in vitro assay correctly identified compounds with reported antifibrotic effects in vivo, targeting diverse cellular pathways (Palano et al., 2020), thus, highlighting its utility for high-throughput screening to discover novel compounds and targets for the treatment of cardiac fibrosis. The HCI assay has several advantages, i.e., (1) screening in high-throughput; (2) analyses in microwell format requiring fewer cells and minimizing the amounts of reagents; and (3) quantification of multiparametric readouts on a singlecell basis. In comparison with other traditional approaches, the in vitro cardiac fibrosis assay coupled with HCI analysis is ideal for large-scale screening and machine learning (ML)-based drug discovery. However, the in vitro phenotypic assay might not be able to fully reflect in vivo conditions of cardiac fibrosis. From the perspective of drug discovery, the hit compounds identified in our in vitro cardiac fibrosis assay need to be validated in more complex systems, such as $3 \mathrm{D}$ models, that could better mimic antifibrotic effects in vivo. In this way, the most promising candidates can be identified and selected for further characterization in animal models of cardiac fibrosis.

\section{Perspective and Outlook}

The incorporation of multiple complex features instead of a single-marker readout reduces the intrinsic bias of any screening assay toward its readout (Abraham et al., 2014). These profiles can be analyzed by ML-based classification of the fibrotic phenotype on a well or single-cell level. HCI-based phenotypic classification also biases an assay toward the desired phenotype that the experimenter used to train the classification algorithm. While unsupervised ML approaches can partly mitigate this bias (Grys et al., 2017), robust validation of the control conditions (e.g., fibrotic and non-fibrotic) by orthogonal methods is essential to ensure that the phenotype, thus, hit compounds, and targets will be biologically relevant (Scannell and Bosley, 2016; Moffat et al., 2017).

Phenotypic drug discovery approaches are especially well suited to discover novel targets or novel compound mechanisms of action. Often, however, it is very resource intensive to deconvolute the hits from a screen. A combination of phenotypic and multiparametric assays, with clustered regularly interspaced short palindromic repeats (CRISPR)-based library screening, provides an attractive alternative. Turner et al. (2020) recently described an image-based CRISPR screening to identify regulators of kidney fibrosis. The authors used $\alpha$-SMA as their main readout, combined with fibroblast proliferation and collagen expression, to identify genetic hits and novel targets in kidney fibrosis (Turner et al., 2020).

Major advantages of HCI compared with, for example, transcriptomics or proteomics are its lower cost and singlecell resolution. As such, HCI is well suited also for the analysis of $3 \mathrm{D}$ models and coculture systems. The increased complexity of these models requires single-cell resolution and analysis of diverse morphological characteristics to leverage their higher physiological relevance. In the long run, incorporation of multiplex staining mass cytometry could further increase the number of cellular markers and analyzed parameters while providing subcellular resolution, further reducing the number of precious cells needed (Giesen et al., 2014). However, 3D models still present major challenges for whole-mount imaging, data storage, image analysis, and data interpretation, warranting investment and further research studies to demonstrate their value to improve drug discovery (reviewed in Booij et al., 2019). The 2D and 3D models need to be carefully compared for their predictive value of in vivo efficacy.

Application of HCI and image analysis using ML-based classifiers, as in our phenotypic cardiac fibrosis assay (see section "A Phenotypic High-Throughput in vitro Cardiac Fibrosis Assay"; Palano et al., 2020), provides a way forward to develop such an assay toward a coculture and/or 3D model. Having set up 
a robust biochemical validation and a toolbox of known in vivo modulators of cardiac fibrosis allows for direct comparison and assay optimization toward increased predictivity of in vivo outcomes and, thus, increased physiological relevance.

It is attractive to envision a multiparametric assay, such as our HCI assay, as the basis of a screening cascade for novel treatments of cardiac fibrosis. The combination of HCI and ML provides a low-cost high-throughput assay for either screening chemical libraries for new equity or screening CRISPR libraries to identify new targets. Counterscreening for TGF- $\beta$ pathway modulation could be a second level to provide an initial indication of the mechanism of action. Hits could then be profiled further downstream the cascade in coculture and/or 3D model that builds on similar $\mathrm{HCI} / \mathrm{ML}$ principles before going in vivo.

Another interesting direction would be to develop multiparametric assays for different pathological models. Fibrosis is a hallmark of different pathologies of HF. Tool compounds that modulate specific phenotypes of fibrosis in vivo could be used to train $\mathrm{ML}$ models to recognize and predict specific mechanisms of actions in in vitro assays. Also, here continued assay development will lead the way, such as to choose physiologically relevant stimuli, cell composition, i.e., coculture, and/or pathology-specific patient cells, and to choose the best readouts to capture different pathologies of HF.

\section{FUTURE DIRECTIONS}

\section{What We Still Need to Know About Fibroblasts}

To better characterize in vitro models of cardiac fibrosis and to get more reliable and translational results, it is important to have a better understanding of the biology of CFs. Cardiac fibrosis is an extremely complex process, and, on one hand, blocking it to restore cardiac function and prevent disease progression into HF is the ultimate aim. On the other hand, once cardiac fibrosis is established, the question is to what extent it can be reversed. A recent study, examining the possibility of phenotypic reversion of fibrosis, found that by inhibiting TGF$\beta 1$ receptor kinase in CFs isolated from cardiac tissue collected from patients, they could promote dedifferentiation of myoFBs and reduce the expression profile of certain profibrotic genes (Nagaraju et al., 2019).

But the question remains whether these findings would translate to an in vivo scenario. Due to their phenotypic plasticity, fibroblasts can be reverted to a quiescent phenotype. Recent studies have shown that CFs can be maintained in a resting state in vitro using elastic silicone substrate (Landry et al., 2019) or can be reversed by culturing them on soft hydrogels or blocking them with inhibitors (Gilles et al., 2020). Using small molecule inhibitors, cardiac fibrosis can be attenuated in mouse models (Wang et al., 2018).

However, the challenges of reversing fibrosis go beyond the properties of fibroblast itself, but they extend to the reabsorption of the ECM by reducing expression of $\alpha$-SMA and production of collagen (Shinde et al., 2017) and to the restoration of the cardiac structure. For this to work, cooperation between all cardiac cell types is needed.

\section{Current in vitro Assays Driving Drug Development}

Currently available in vitro assays have contributed to drug candidates targeting cardiac fibrosis, such as TGF- $\beta$ inhibitors, renin-angiotensin-aldosterone system (RAAS) inhibitors, endothelin inhibitors, MMP inhibitors, relaxin, and others (reviewed in Fang et al., 2017). Their failure in clinical trials highlights the need for more physiologically relevant assays to discover new antifibrotic drugs.

In a recent study, a novel antifibrotic therapeutic based on a naturally derived substance was developed using two different hypertension-dependent rodent models (Schimmel et al., 2020). These antifibrotic drug candidates were identified by functional screening of 480 chemically diverse natural compounds in primary human CFs, subsequent validation, and mechanistic in vitro and in vivo studies. High-throughput natural compound library screening identified 15 substances with antiproliferative effects. Hits were analyzed for dose-dependent inhibition of proliferation, modulation of apoptosis, and expression of ECM. Using multiple in vitro fibrosis assays and stringent selection algorithms, the authors identified the steroid bufalin and the alkaloid lycorine to be effective antifibrotic molecules both in vitro and in vivo. These in vitro findings were confirmed in vivo with an angiotensin II-mediated murine model of cardiac fibrosis in both preventive and therapeutic settings and in the Dahl salt-sensitive rat model (Schimmel et al., 2020). Another study, using NIH 3T3 mouse fibroblasts, demonstrated that long noncoding RNA (lncRNA) Neat1 has important functions for fibroblast survival, migration, and proliferation. These findings were confirmed in a MI model using the genetic loss of Neat1 mice (Kenneweg et al., 2019). Likewise, noncoding RNAs, such as miRNA-21, miR-208a, and Meg 3, have recently emerged as promising targets (Piccoli et al., 2017; Kenneweg et al., 2019). Studies like these promote new angles for therapeutic approaches with regard to antifibrotic agents and highlight the translational importance of well-established in vitro assays for the discovery of novel targets and development of drugs against cardiac fibrosis.

\section{CONCLUSIONS: WHERE ARE WE HEADING?}

The switch from immortalized cell lines to primary cells, cocultures, and 3D models is a step forward in filling the translational gap. The use of more physiologically relevant in vitro models in preclinical development will lead to drugs having better efficacy and safety parameters in vivo and in the clinic. For in vitro effects to translate to in vivo, it is essential that the in vitro assay readout is predictive for in vivo effects. For cardiac fibrosis, assays with single, welldefined readouts have shown only limited translatability toward in vivo. Multiparametric readouts, such as omics or highcontent techniques, provide a way forward, integrating a holistic, phenotypic fibrotic response. HCI provides a multiparametric 
readout at low costs, suitable for high-throughput screening, and it allows analysis on a single-cell level thus supporting analysis of cocultures and 3D models. These advantages make HCI and ML-based data analysis our method of choice for multiparametric assessment of cardiac fibrosis. As these new approaches come not without challenges and the need for investments, there remains a strong need for these technologies and each in vitro assay setup to clearly demonstrate improved predictivity toward in vivo and ultimately translation to the clinics. Ideally, in vitro assay setups are cross validated with collections of molecules that have confirmed the benefits of treating cardiac fibrosis in vivo. In addition, Booij et al. (2019) suggested that multiparametric phenotypic approaches allow us to determine a footprint of successful medicines and optimize new drugs toward this.

Multiple different pieces are coming together toward developing a physiologically relevant, predictive, and highthroughput in vitro assay for novel treatments against cardiac

\section{REFERENCES}

Abonnenc, M., Nabeebaccus, A. A., Mayr, U., Barallobre-Barreiro, J., Dong, X., Cuello, F., et al. (2013). Extracellular matrix secretion by cardiac fibroblasts: role of microRNA-29b and microRNA-30c. Circ. Res. 113, 1138-1147. doi: 10.1161/circresaha.113.302400

Abraham, Y., Zhang, X., and Parker, C. N. (2014). Multiparametric analysis of screening data: growing beyond the single dimension to infinity and beyond. J. Biomol. Screen 19, 628-639. doi: 10.1177/10870571145 24987

Aujla, P. K., and Kassiri, Z. (2021). Diverse origins and activation of fibroblasts in cardiac fibrosis. Cell Signal. 78:109869. doi: 10.1016/j.cellsig.2020. 109869

Barallobre-Barreiro, J., Didangelos, A., Schoendube, F. A., Drozdov, I., Yin, X., Fernandez-Caggiano, M., et al. (2012). Proteomics analysis of cardiac extracellular matrix remodeling in a porcine model of ischemia/reperfusion injury. Circulation 125, 789-802. doi: 10.1161/circulationaha.111. 056952

Baranyi, U., Winter, B., Gugerell, A., Hegedus, B., Brostjan, C., Laufer, G., et al. (2019). Primary human fibroblasts in culture switch to a myofibroblastlike phenotype independently of TGF Beta. Cells 8:721. doi: 10.3390/cells80 70721

Baudino, T. A., McFadden, A., Fix, C., Hastings, J., Price, R., and Borg, T. K. (2008). Cell patterning: interaction of cardiac myocytes and fibroblasts in three-dimensional culture. Microsc. Microanal. 14, 117-125. doi: 10.1017/ s1431927608080021

Booij, T. H., Price, L. S., and Danen, E. H. J. (2019). 3D cell-based assays for drug screens: challenges in imaging, image analysis, and highcontent analysis. SLAS Discov. 24, 615-627. doi: 10.1177/24725552198 30087

Bryant, J. E., Shamhart, P. E., Luther, D. J., Olson, E. R., Koshy, J. C., Costic, D. J., et al. (2009). Cardiac myofibroblast differentiation is attenuated by alpha(3) integrin blockade: potential role in post-MI remodeling. J. Mol. Cell Cardiol. 46, 186-192. doi: 10.1016/j.yjmcc.2008.10.022

Canty, E. G., and Kadler, K. E. (2005). Procollagen trafficking, processing and fibrillogenesis. J. Cell Sci. 118(Pt 7), 1341-1353. doi: 10.1242/jcs.01731

Chothani, S., Schafer, S., Adami, E., Viswanathan, S., Widjaja, A. A., Langley, S. R., et al. (2019). Widespread translational control of fibrosis in the human heart by RNA-binding proteins. Circulation 140, 937-951.

Desmouliere, A., Geinoz, A., Gabbiani, F., and Gabbiani, G. (1993). Transforming growth factor-beta 1 induces alpha-smooth muscle actin expression in granulation tissue myofibroblasts and in quiescent and growing cultured fibroblasts. J. Cell Biol. 122, 103-111. doi: 10.1083/jcb.122. 1.103 fibrosis. While the ideal will likely never be reached, the substantial improvements made in recent years will lead to a better and earlier prediction of drug efficacy and identification of novel antifibrotic drug mechanisms and, thereby, will reduce failures, cost, and time in clinical trials.

\section{AUTHOR CONTRIBUTIONS}

All authors were involved in the design and writing of this manuscript.

\section{ACKNOWLEDGMENTS}

The authors thank Katharina Schimmel and Bramasta Nugraha for critical proofreading and valuable input for the manuscript.

Fang, L., Murphy, A. J., and Dart, A. M. A. (2017). Clinical perspective of anti-fibrotic therapies for cardiovascular disease. Front. Pharmacol. 8:186.

Filippo Buono, M., von Boehmer, L., Strang, J., Hoerstrup, S. P., Emmert, M. Y., and Nugraha, B. (2020). Human cardiac organoids for modeling genetic cardiomyopathy. Cells 9:1733. doi: 10.3390/cells90 71733

Gabbiani, G., Ryan, G. B., and Majne, G. (1971). Presence of modified fibroblasts in granulation tissue and their possible role in wound contraction. Experientia 27, 549-550. doi: 10.1007/bf02147594

Giesen, C., Wang, H. A., Schapiro, D., Zivanovic, N., Jacobs, A., Hattendorf, B., et al. (2014). Highly multiplexed imaging of tumor tissues with subcellular resolution by mass cytometry. Nat. Methods 11, 417-422. doi: 10.1038/nmeth. 2869

Gilles, G., McCulloch, A. D., Brakebusch, C. H., and Herum, K. M. (2020). Maintaining resting cardiac fibroblasts in vitro by disrupting mechanotransduction. PLoS One 15:e0241390. doi: 10.1371/journal.pone. 0241390

Grande, J. P., Melder, D. C., and Zinsmeister, A. R. (1997). Modulation of collagen gene expression by cytokines: stimulatory effect of transforming growth factorbeta1, with divergent effects of epidermal growth factor and tumor necrosis factor-alpha on collagen type I and collagen type IV. J. Lab. Clin. Med. 130, 476-486. doi: 10.1016/s0022-2143(97)90124-4

Grys, B. T., Lo, D. S., Sahin, N., Kraus, O. Z., Morris, Q., Boone, C., et al. (2017). Machine learning and computer vision approaches for phenotypic profiling. J. Cell Biol. 216, 65-71. doi: 10.1083/jcb.201610026

Heymans, S., Gonzalez, A., Pizard, A., Papageorgiou, A. P., Lopez-Andres, N., Jaisser, F., et al. (2015). Searching for new mechanisms of myocardial fibrosis with diagnostic and/or therapeutic potential. Eur. J. Heart Fail. 17, 764-771. doi: 10.1002/ejhf.312

Horvath, P., Aulner, N., Bickle, M., Davies, A. M., Nery, E. D., Ebner, D., et al. (2016). Screening out irrelevant cell-based models of disease. Nat. Rev. Drug Discov. 15, 751-769. doi: 10.1038/nrd.2016.175

Jonsson, M. K. B., Hartman, R. J. G., Ackers-Johnson, M., Tan, W. L. W., Lim, B., van Veen, T. A. B., et al. (2016). A transcriptomic and epigenomic comparison of fetal and adult human cardiac fibroblasts reveals novel key transcription factors in adult cardiac fibroblasts. JACC Basic Transl. Sci. 1, 590-602. doi: 10.1016/j.jacbts.2016.07.007

Junqueira, L. C., Bignolas, G., and Brentani, R. R. (1979). Picrosirius staining plus polarization microscopy, a specific method for collagen detection in tissue sections. Histochem J. 11, 447-455. doi: 10.1007/bf010 02772

Kenneweg, F., Bang, C., Xiao, K., Boulanger, C. M., Loyer, X., Mazlan, S., et al. (2019). Long Noncoding RNA-enriched vesicles secreted by hypoxic 
cardiomyocytes drive cardiac fibrosis. Mol. Ther. Nucleic Acids 18, 363-374. doi: 10.1016/j.omtn.2019.09.003

Kong, P., Christia, P., and Frangogiannis, N. G. (2014). The pathogenesis of cardiac fibrosis. Cell Mol. Life Sci. 71, 549-574.

Landry, N. M., Rattan, S. G., and Dixon, I. M. C. (2019). An improved method of maintaining primary murine cardiac fibroblasts in two-dimensional cell culture. Sci. Rep. 9:12889.

Lee, M. O., Jung, K. B., Jo, S. J., Hyun, S. A., Moon, K. S., Seo, J. W., et al. (2019). Modelling cardiac fibrosis using three-dimensional cardiac microtissues derived from human embryonic stem cells. J. Biol. Eng. 13:15.

Li, M., Luan, F., Zhao, Y., Hao, H., Zhou, Y., Han, W., et al. (2016). Epithelial-mesenchymal transition: an emerging target in tissue fibrosis. Exp. Biol. Med. (Maywood) 241, 1-13. doi: 10.1177/15353702155 97194

Liang, C. C., Park, A. Y., and Guan, J. L. (2007). In vitro scratch assay: a convenient and inexpensive method for analysis of cell migration in vitro. Nat. Protoc. 2, 329-333. doi: 10.1038/nprot.2007.30

Litvinukova, M., Talavera-Lopez, C., Maatz, H., Reichart, D., Worth, C. L., Lindberg, E. L., et al. (2020). Cells of the adult human heart. Nature 588, $466-472$.

Liu, T., Song, D., Dong, J., Zhu, P., Liu, J., Liu, W., et al. (2017). Current understanding of the pathophysiology of myocardial fibrosis and its quantitative assessment in heart failure. Front. Physiol. 8:238.

Moffat, J. G., Vincent, F., Lee, J. A., Eder, J., and Prunotto, M. (2017). Opportunities and challenges in phenotypic drug discovery: an industry perspective. Nat. Rev. Drug Discov. 16, 531-543. doi: 10.1038/nrd.2017.111

Murdoch, C. E., Chaubey, S., Zeng, L., Yu, B., Ivetic, A., Walker, S. J., et al. (2014). Endothelial NADPH oxidase-2 promotes interstitial cardiac fibrosis and diastolic dysfunction through proinflammatory effects and endothelialmesenchymal transition. J. Am. Coll. Cardiol. 63, 2734-2741. doi: 10.1016/j. jacc.2014.02.572

Nagaraju, C. K., Robinson, E. L., Abdesselem, M., Trenson, S., Dries, E., Gilbert, G., et al. (2019). Myofibroblast phenotype and reversibility of fibrosis in patients with end-stage heart failure. J. Am. Coll. Cardiol. 73, 2267-2282. doi: 10.1016/ j.jacc.2019.02.049

Nugraha, B., Buono, M. F., and Emmert, M. Y. (2018). Modelling human cardiac diseases with 3D organoid. Eur. Heart J. 39, 4234-4237. doi: 10.1093/eurheartj/ ehy765

Nugraha, B., Buono, M. F., von Boehmer, L., Hoerstrup, S. P., and Emmert, M. Y. (2019). Human cardiac organoids for disease modeling. Clin. Pharmacol. Ther. 105, 79-85. doi: 10.1002/cpt.1286

Palano, G., Jansson, M., Backmark, A., Martinsson, S., Sabirsh, A., Hultenby, K., et al. (2020). A high-content, in vitro cardiac fibrosis assay for high-throughput, phenotypic identification of compounds with anti-fibrotic activity. J. Mol. Cell Cardiol. 142, 105-117. doi: 10.1016/j.yjmcc.2020. 04.002

Pantazis, P., Maloney, J., Wu, D., and Fraser, S. E. (2010). Second harmonic generating (SHG) nanoprobes for in vivo imaging. Proc. Natl. Acad. Sci. U.S.A. 107, 14535-14540. doi: 10.1073/pnas.1004748107

Piccoli, M. T., Gupta, S. K., Viereck, J., Foinquinos, A., Samolovac, S., Kramer, F. L., et al. (2017). Inhibition of the cardiac fibroblast-enriched lncRNA Meg3 prevents cardiac fibrosis and diastolic dysfunction. Circ. Res. 121, 575-583. doi: 10.1161/circresaha.117.310624

Pinto, A. R., Ilinykh, A., Ivey, M. J., Kuwabara, J. T., D’Antoni, M. L., Debuque, R., et al. (2016). Revisiting cardiac cellular composition. Circ. Res. 118, 400-409. doi: 10.1161/circresaha.115.307778

Polonchuk, L., Chabria, M., Badi, L., Hoflack, J. C., Figtree, G., Davies, M. J., et al. (2017). Cardiac spheroids as promising in vitro models to study the human heart microenvironment. Sci Rep. 7, 7005.

Qiu, B., Wei, F., Sun, X., Wang, X., Duan, B., Shi, C., et al. (2014). Measurement of hydroxyproline in collagen with three different methods. Mol. Med. Rep. 10, 1157-1163. doi: 10.3892/mmr.2014.2267

Querejeta, R., Lopez, B., Gonzalez, A., Sanchez, E., Larman, M., Martinez Ubago, J. L., et al. (2004). Increased collagen type I synthesis in patients with heart failure of hypertensive origin: relation to myocardial fibrosis. Circulation 110, 1263-1268. doi: 10.1161/01.cir.0000140973.60992.9a
Querejeta, R., Varo, N., Lopez, B., Larman, M., Artinano, E., Etayo, J. C., et al. (2000). Serum carboxy-terminal propeptide of procollagen type I is a marker of myocardial fibrosis in hypertensive heart disease. Circulation 101, 1729-1735. doi: 10.1161/01.cir.101.14.1729

Ranganathan, P., Agrawal, A., Bhushan, R., Chavalmane, A. K., Kalathur, R. K., Takahashi, T., et al. (2007). Expression profiling of genes regulated by TGFbeta: differential regulation in normal and tumour cells. BMC Genomics 8:98. doi: 10.1186/1471-2164-8-98

Rehman, M., Vodret, S., Braga, L., Guarnaccia, C., Celsi, F., Rossetti, G., et al. (2019). High-throughput screening discovers antifibrotic properties of haloperidol by hindering myofibroblast activation. JCI Insight 4: e123987.

Sahadevan, P., and Allen, B. G. (2021). Isolation and culture of adult murine cardiac atrial and ventricular fibroblasts and myofibroblasts. Methods (in press).

Santiago, J. J., Dangerfield, A. L., Rattan, S. G., Bathe, K. L., Cunnington, R. H., Raizman, J. E., et al. (2010). Cardiac fibroblast to myofibroblast differentiation in vivo and in vitro: expression of focal adhesion components in neonatal and adult rat ventricular myofibroblasts. Dev. Dyn. 239, 1573-1584. doi: 10.1002/ dvdy. 22280

Scannell, J. W., and Bosley, J. (2016). When quality beats quantity: decision theory, drug discovery, and the reproducibility crisis. PLoS One 11:e0147215. doi: 10.1371/journal.pone. 0147215

Scheeder, C., Heigwer, F., and Boutros, M. (2018). Machine learning and imagebased profiling in drug discovery. Curr. Opin. Syst. Biol. 10, 43-52. doi: 10. 1016/j.coisb.2018.05.004

Schimmel, K., Jung, M., Foinquinos, A., Jose, G. S., Beaumont, J., Bock, K., et al. (2020). Natural compound library screening identifies new molecules for the treatment of cardiac fibrosis and diastolic dysfunction. Circulation 141, 751-767.

Sharma, U. C., Pokharel, S., van Brakel, T. J., van Berlo, J. H., Cleutjens, J. P., Schroen, B., et al. (2004). Galectin-3 marks activated macrophages in failureprone hypertrophied hearts and contributes to cardiac dysfunction. Circulation 110, 3121-3128. doi: 10.1161/01.cir.0000147181.65298.4d

Shinde, A. V., Humeres, C., and Frangogiannis, N. G. (2017). The role of alpha-smooth muscle actin in fibroblast-mediated matrix contraction and remodeling. Biochim. Biophys. Acta Mol. Basis Dis. 1863, 298-309. doi: 10.1016/ j.bbadis.2016.11.006

Sieber, P., Schafer, A., Lieberherr, R., Le Goff, F., Stritt, M., Welford, R. W. D., et al. (2018). Novel high-throughput myofibroblast assays identify agonists with therapeutic potential in pulmonary fibrosis that act via EP2 and EP4 receptors. PLoS One 13:e0207872. doi: 10.1371/journal.pone.0207872

Skalli, O., Pelte, M. F., Peclet, M. C., Gabbiani, G., Gugliotta, P., Bussolati, G., et al. (1989). Alpha-smooth muscle actin, a differentiation marker of smooth muscle cells, is present in microfilamentous bundles of pericytes. J. Histochem. Cytochem. 37, 315-321. doi: 10.1177/37.3.2918221

Tesseur, I., Zou, K., Berber, E., Zhang, H., and Wyss-Coray, T. (2006). Highly sensitive and specific bioassay for measuring bioactive TGF-beta. BMC Cell Biol. $7: 15$.

Turner, R. J., Golz, S., Wollnik, C., Burkhardt, N., Sternberger, I., Andag, U., et al. (2020). A Whole genome-wide arrayed CRISPR screen in primary organ fibroblasts to identify regulators of kidney fibrosis. SLAS Discov. 25, 591-604. doi: $10.1177 / 2472555220915851$

van Huizen, N. A., Ijzermans, J. N. M., Burgers, P. C., and Luider, T. M. (2020). Collagen analysis with mass spectrometry. Mass Spectrom. Rev. 39, 309-335. doi: $10.1002 /$ mas. 21600

Wang, Z., Stuckey, D. J., Murdoch, C. E., Camelliti, P., Lip, G. Y. H., and Griffin, M. (2018). Cardiac fibrosis can be attenuated by blocking the activity of transglutaminase 2 using a selective small-molecule inhibitor. Cell Death Dis. 9:613.

Warchal, S. J., Unciti-Broceta, A., and Carragher, N. O. (2016). Next-generation phenotypic screening. Future Med. Chem. 8, 1331-1347. doi: 10.4155/fmc2016-0025

Weigle, S., Martin, E., Voegtle, A., Wahl, B., and Schuler, M. (2019). Primary cellbased phenotypic assays to pharmacologically and genetically study fibrotic diseases in vitro. J. Biol. Methods 6:e115. doi: 10.14440/jbm.2019.285

Whittaker, P., Kloner, R. A., Boughner, D. R., and Pickering, J. G. (1994). Quantitative assessment of myocardial collagen with picrosirius red staining 
and circularly polarized light. Basic Res. Cardiol. 89, 397-410. doi: 10.1007/ bf00788278

Yndestad, A., Landro, L., Ueland, T., Dahl, C. P., Flo, T. H., Vinge, L. E., et al. (2009). Increased systemic and myocardial expression of neutrophil gelatinaseassociated lipocalin in clinical and experimental heart failure. Eur. Heart J. 30, 1229-1236. doi: 10.1093/eurheartj/ehp088

Zhang, Y. E. (2017). Non-smad signaling pathways of the TGF-beta Family. Cold Spring Harb. Perspect. Biol. 9:a022129. doi: 10.1101/cshperspect.a0 22129

Zuppinger, C. (2019). 3D cardiac cell culture: a critical review of current technologies and applications. Front. Cardiovasc. Med. 6:87.
Conflict of Interest: AF and EM are employees of AstraZeneca.

The remaining author declares that the research was conducted in the absence of any commercial or financial relationships that could be construed as a potential conflict of interest.

Copyright ( 2021 Palano, Foinquinos and Müllers. This is an open-access article distributed under the terms of the Creative Commons Attribution License (CC BY). The use, distribution or reproduction in other forums is permitted, provided the original author(s) and the copyright owner(s) are credited and that the original publication in this journal is cited, in accordance with accepted academic practice. No use, distribution or reproduction is permitted which does not comply with these terms. 